Short Communication

\title{
Effect of Silicon Addition on Corrosion Behavior of Carbon Steel Rebar in Sulfuric Acid Environment
}

\author{
Hui Zhou, Yujie Wang*, Tengfei Ma \\ Department of Architectural Engineering, North China Institute of Aerospace Engineering, Hebei, \\ Langfang 065000, China \\ *E-mail: wangyj_80@foxmail.com
}

doi: $10.20964 / 2020.04 .22$

Received: 5 December 2019 / Accepted: 27 January 2020 / Published: 10 March 2020

\begin{abstract}
Effects of silicon as an alloying element on corrosion resistance of carbon steel rebar in sulfuric acid environment were studied by a mass loss, polarization, open circuit potential and electrochemical impedance spectroscopy (EIS) analysis. The polarization results indicated that the corrosion potential was shifted to the more noble direction and the current density at the anode decreased slightly because of the Si addition. Based on EIS results, increasing the Si content revealed a significantly enhancement in the value of polarization resistance, indicating a high corrosion resistance of $0.9 \mathrm{wt} \% \mathrm{Si}$ sample. The mass loss measurements exhibited a reduction of mass loss rate in carbon steel rebar with the increase of Si content which was in full accordance with the results of EIS analysis. The surface morphology of the carbon steel indicated a superlative more uneven and rough compared to the Si-containing steel reinforced concrete after 8 weeks exposure to the sulfuric acid environment.
\end{abstract}

Keywords: Alloyed carbon steel rebar; Silicon; Corrosion resistance; Electrochemical impedance spectroscopy; Reinforced concrete

\section{$\underline{\text { FULL TEXT }}$}

(C) 2020 The Authors. Published by ESG (www.electrochemsci.org). This article is an open access article distributed under the terms and conditions of the Creative Commons Attribution license (http://creativecommons.org/licenses/by/4.0/). 